\title{
The Distribution Pattern of Alkylphenol Polyethoxylates (APEOs) in Aquatic Environment of Kaohsiung Area, Taiwan
}

\author{
Ping-Chang Ku' ${ }^{1}$, Te-An Gong' ${ }^{2}$, Wei-Hsien Wang ${ }^{3}$ \\ ${ }^{1,2,3}$ Department of Marine Biotechnology and Resources, National Sun Yet-Sen University, 70 Lien-Hai Road, \\ Kaohsiung 80424, Taiwan, ROC \\ pcku0912@gmail.com; pop3887@yahoo.com.tw; whw@mail.nsysu.edu.tw
}

\section{Extended Abstract}

Nonionic surfactant alkylphenol polyethoxylates (APEOs) are widely used as detergents, emulsifiers, dispersants and wetting agents in industrial, agricultural and domestic applications. It is estimated that about $60 \%$ of the used APEOs entered the aquatic environment through municipal and industrial wastewater discharges. The APEOs in aquatic environment are degraded mainly by subsequently loss of the ethoxy groups and ultimately transformed to alkylphenols (APs) which are known as endocrine disrupting substances to aquatic organisms. APs can bind to the estrogen receptor to simulate the function of 17ß-estradiol due to their similar chemical conformation, and therefore, has caused increasing concern about their impact to aquatic wildlife and human health. The aim of this study was to determine the APEOs in aquatic environments of the harbor city Kaohsiung which is the second largest city in Taiwan with a population of two million.

Water samples were collected from Love River (16 sampling sites, R1 R16), Kaohsiung Harbor (5 sampling sites, H1 H5) and coastal area where domestic sewage of Kaohsiung City was discharged (10 sampling sites, S1 S10). The Love River flowed through the populous area in Kaohsiung City and poured into Kaohsiung Harbor. The collected water samples were filtered through glass fiber filter paper (Whatman, GF/C) and then extracted with $1 \mathrm{~mL}$ of isooctane/n-octanol solvent mixture $(8: 2 / \mathrm{v}: \mathrm{v})$. The organic layer was collected and analyzed with HPLC-ESI-MS/MS consisted of an Agilent series 1100 HPLC system connected to a Sciex API 4000 triple-stage quadrupole (QqQ) mass spectrometer. HPLC analysis was performed on a C18 reversed-phase column $(4.6 \times 150 \mathrm{~mm}, 5 \mu \mathrm{m}$; Agilent, ZORBAX SB-C18) at room temperature. Multiplereaction monitoring (MRM) mode of the QqQ mass spectrometry was chosen to determine all the APEOs (nonyl- and octylphenol with EO number $\mathrm{n}=0 \sim 12$ ).

The results showed that, in Love River, the total concentration of APEOs presented high coefficient of correlation with salinity $\left(\mathrm{R}^{2}=0.82\right.$ for NPEOs, 0.817 for OPEOs). APEOs concentration were much higher at $\mathrm{R} 15(17.2 \pm 0.87 \mu \mathrm{g} / \mathrm{L})$ and $\mathrm{R} 16(9.62 \pm 0.34 \mu \mathrm{g} / \mathrm{L})$ than at R1 R14 $(0.66 \sim 2.59 \mu \mathrm{g} / \mathrm{L})$. These observations were attributed to the interception sluice between R14 and R15 which intercepted and accumulated the untreated sewage from nearby and upper stream areas. APEOs at R15 and R16 had longer and more uniformly distributed EO chain length than the lower stream sampling sites (R1 R14) along Love River. This might be due to the APEOs in the water bodies of R15 and R16 were fresh from the intercepted and accumulated domestic sewage. APEOs concentrations ranging from 0.74 to $2.50 \mu \mathrm{g} / \mathrm{L}$ were found at Kaohsiung Harbor sampling sites (H1 H5). The EO chain length distribution pattern for APEOs in Kaohsiung Harbor (H1 H5) was similar to lower stream of Love River (R1 R14). It could be ascribed to the water bodies of Kaohsiung Harbor and Love River were well-mixed through tidal exchange. APEOs concentrations in coastal water (S1 S10) were between 0.08 and $13.2 \mu \mathrm{g} / \mathrm{L}$. Different from Kaohsiung Harbor and lower stream of Love River, the distribution pattern of APEOs in coastal water was similar to R15 and R16 at the upper stream of Love River which were longer and more uniform in EO chain length. We suggested that APEOs contained in the sewage effluent discharged from the treatment plant to coastal waters were as "fresh" as those in the waters intercepted at R15 and R16 of Love River. Further studies on the degradation rate and the residence time of APEOs in the aquatic environment around Kaohsiung will be conducted. The results will serve as vital data for the environmental risk assessment associated with APEOs and coastal water management of Kaohsiung area and elsewhere. 